\title{
IMPACT OF SILVER NANOPARTICLES ON GERMINATION AND GROWTH FEATURES IN MUNG BEAN PLANT (Vigna radiata)
}

\author{
Dr. Febina Bernice Sharon \\ Department of Food Science and Nutrition \\ Sarah Tucker College, Tirunelveli, Tamil Nadu, India
}

\begin{abstract}
The present study investigated the effects of different concentrations of silver nanoparticle on various plant growth parameters of Vigna radiata plant. The nanoparticles were synthesized from a bacterium, Klebsiella pneumoniae strain STC4 and were confirmed by UV spectrophotometer and Transmission electron microscope. Various parts of Vigna radiata were subjected to Atomic Absorption Spectrophotometer analysis to study the accumulation of silver nanoparticles. The results showed that small concentrations of silver nanoparticles had a stimulating effect on the growth of plantlets, while the largest concentration induced an inhibitory effect. However, increasing concentration of silver nanoparticles from 2000 to $6000 \mathrm{ppm}$ had led to increase in germination frequency, shoot length, leaf surface area, chlorophyll and carotenoid content. There was no significant difference in root length and number of leaves. In the AAS analysis, it was found that roots of mung bean plant accumulated more silver nanoparticles than other parts indicating its phytostabilization property.
\end{abstract}

Keywords - silver nanoparticles, Transmission electron microscope, Vigna radiata, seed germination, AAS.

\section{INTRODUCTION}

Nanotechnology, a developing technology in India, opens a large scope of innovative applications in biotechnology and agricultural areas. In the past 10 years, nanotechnology has been extensively useful in the agriculture sector and the nanoparticles are often incorporated into nano-formulated fertilizers and pesticides for protection of crops [1]. It also acts as plant-growth stimulators [2], fungicides to prevent fungal diseases [3], or agents to enhance fruit ripening [4]. The growing consumption of nanoparticles certainly increases the chance of release of the nanoparticles into the environment during its synthesis, incorporation into products, during handling, recycling or disposal of these products $[5,6]$. The nanoparticles are indeed accumulating in the soil or water reservoirs in greater quantities [7].

The plants roots absorb nutrients, water, and contaminants from their growing environment. As the plants may assist as a

\author{
D. Sumithra, G. Sangeetha \\ Department of Nano Science, \\ Sarah Tucker College, Tirunelveli, Tamil Nadu, India
}

potential pathway for the transportation of nanoparticles through the food chain [8], the growing applications of engineered nanomaterial in the world have raised a growing concern about their potential adverse impacts on ecosystems, food safety and human health [9]. Therefore, to evaluate possible environmental risks imposed by nanoparticle application, it is significant to understand the interaction between nanoparticles and plants, as well as the performance and harmfulness of nanoparticles in plants. Nevertheless, the performance of nanoparticles in plants and phytotoxicity mechanism are so intricate that contrary outcomes regarding the effects of nanoparticles on the plants were attained from numerous studies during the previous decade $[10,11]$.

Different types of nanoparticles exhibit discrete behaviours and translocation features. During interaction with biological environments, nanoparticles can be transformed by plants, which in turn alter environmental fate and toxic properties of nanoparticles $[12,13]$. Therefore, the toxicity and behaviour of nanoparticles are determined by not only shape, structure, particle size, charge, mass concentration, elemental composition, and state of aggregation etc., but also by the physicochemical evolution [14]. Henceforth, in order to precisely evaluate the phytotoxicity of nanoparticles, it is necessary to determine the original features of nanoparticles before treatment, uptake and translocation, cellular internalization and intracellular biotransformation during interaction with plants.

Silver is the second deadly metal to aquatic creatures after mercury [15]. In fact, silver nanoparticles can leach silver ions, which are persistent, bio accumulative, and highly toxic to organisms [2]. Consequently, the silver nanoparticles release into ecosystems increases huge concerns about ecological toxicity. The plants are an important part of ecosystem because the primary trophic level in ecosystems represents the base of the food chain [16]. Therefore a good understanding between the impacts of silver nanoparticles on plants is of paramount importance for assessing its toxicity. Hence, the present study examined the growth parameters, uptake and translocation of silver nanoparticles on Vigna radiata plant. 


\section{MATERIALS AND METHODS}

\section{A. Isolation and characterization of bacteria}

The bacterium was isolated from bovine milk sample by serial dilution spread plate technique. DNA was extracted from the bacterial colonies and amplified by PCR. The product of PCR was sequenced using following primers.

\section{Forward (5'AGAGTTTGATCCTGGCTCAG3') \\ Reverse (5'AAGGAGGTGATCCAGCCGCA3')}

The PCR primers and dNTPs which were excess in solution was removed by using Montage PCR Clean-up kit. The 16S rRNA sequencing reactions were done by ABI PRISM® BigDyeTM Terminator Cycle Sequencing Kits using AmpliTaq ${ }^{\circledR}$ DNA polymerase. The $16 \mathrm{~S}$ rRNA sequences were compared with other nucleotide sequences, maintained by GenBank database, using NCBI-BLAST program. Finally $16 \mathrm{~S}$ rRNA sequences were aligned by CLUSTAL $\mathrm{W}$ and the phylogenetic tree was constructed using Maximum Likelihood method in MEGA X.

\section{B. Preparation of microbial extract}

The fresh culture of the bacterium was inoculated in Nutrient Broth (Himedia) and kept in rotary shaker for 24 hours at $100 \mathrm{rpm}$. The broth with the cells was centrifuged for 20 minutes at $5200 \mathrm{rpm}$ and supernatant was collected.

\section{Biosynthesis and Characterization of silver nanoparticles}

$500 \mathrm{ml}$ of the supernatant was mixed with $250 \mathrm{ml}$ $(10 \mathrm{mM})$ of silver nitrate (Fisher Scientific) solution and another reaction mixture without silver nitrate was used as control. The prepared solutions were incubated at $30^{\circ} \mathrm{C}$ for 24 hours in dark to avoid photochemical reactions. The silver nanoparticles were purified after the incubation by centrifugation for 30 minutes at 5,200rpm and collected for further characterization by UV-visible spectrophotometer.

The size and shape of nanoparticles was investigated by High Resolution Transmission Electron Microscopy (HRTEM). The silver nanoparticles were prepared by dropping a small amount on copper grid and extra sample was removed by using blotting paper, and it was kept for drying at room temperature for 15-30 minutes. HR-TEM instrument (JOELJEM 2100) was operated at an accelerated voltage at $200 \mathrm{kV}$.

\section{Seed selection, treatment and Inoculation}

The mung bean seeds were purchased from a local store in Tirunelveli, Tamil Nadu, India. One hundred mung bean seeds of similar size were randomly selected and immersed in $75 \%$ ethanol for a minute to ensure surface sterility. The silver nanoparticles were added to the seeds at the concentration of 2000ppm, 4000ppm, 6000ppm, 8000ppm and $10000 \mathrm{ppm}$ for about 4 hours after being rinsed three times with distilled water. Few seeds were soaked in distilled water, and kept as control. 1.5\% of agar solution was prepared, sterilized and poured onto the pre-sterilized beakers. The soaked seeds were inoculated on to the surface of the medium by pressing on agar to ensure good contact. The beakers were covered with paper and tied.

\section{E. Seed germination frequency}

The beakers were kept at dark for seeds germination. The number of germinated seeds was counted at 24 and 48 hours. Germination percentage was calculated using the formula [17],

Germination percentage $=($ Number of seeds germinated $/$ Total number of seeds) x 100

\section{F. Growth measurement of mung bean plant}

The beakers were left open after the germination. Distilled water was sprinkled over the plants. Root length, shoot length and number of leaves were recorded on day 4 and day 7 . The healthy plants were transferred to pot filled with fertile loam soil up to $3 / 4$ the height of the pot. The plants were measured using the ruler on the $15^{\text {th }}$ day, and they were harvested for further analysis. Fresh and dry weights, leaf surface area were measured. Seedling vigour was computed based on the formula [17]

Vigour index $=$ Germination percentage $($ Mean shoot length + Mean root length)

\section{G. Estimation of chlorophyll}

In a mortar, 0.5 grams of fresh plant was placed and macerated. The process was carried out in the dim light. To the macerate, $4 \mathrm{ml}$ of $99 \%$ acetone and $2 \mathrm{ml}$ ethanol were added and stirred for 1 minute to ensure complete contact of the plant material. The plant extract was kept in freezer for 30 minutes, and then centrifuged for 10 minutes at 2000rpm. The supernatant was mixed with $5 \mathrm{ml}$ of acetone/ethanol in the ratio 2:1 and stirred for 1 minute. Absorbance was taken at wavelengths of $645 \mathrm{~nm}$ and $663 \mathrm{~nm}$. Acetone/ethanol (2:1) was used as control. The obtained values were substituted in the following formulas for the estimation of photosynthetic pigments [18].

$$
\begin{aligned}
& \text { Chlorophyll a }(\mathrm{mg} / \mathrm{g})=(12.7 * \mathrm{~A} 663)-(2.59 * \mathrm{~A} 645) \\
& \text { Chlorophyll b }(\mathrm{mg} / \mathrm{g})=(22.9 * \mathrm{~A} 645)-(4.7 * \mathrm{~A} 663) \\
& \text { Chlorophyll total }(\mathrm{mg} / \mathrm{g})=(8.2 * \mathrm{~A} 663)+(20.2 * \mathrm{~A} 645)
\end{aligned}
$$

Where A663 and A645 were the absorbance measured from $663 \mathrm{~nm}$ and $645 \mathrm{~nm}$ respectively.

\section{H. Estimation of carotenoid}

The method of Lichtenthaler and Welburn in 1983 was used to estimate carotenoid content [19]. 0.5 grams of fresh leaves were taken and homogenized in $10 \mathrm{ml}$ of acetone ( $80 \%$ acetone) and centrifuged at 3000 rpm for 10 minutes, and 
then supernatant was collected and absorbance was recorded at $470 \mathrm{~nm}$.

The carotenoid content is calculated by using the formula

Total carotenoids $=[1000$ A470 $-(2.270$ Chlorophyll a -81.4 Chlorophyll b)] / 227

\section{Microscopic observation}

The leaves, shoot, and root of the mung bean plant were sectioned and observed under light microscope at $10 \mathrm{X}$ and $40 \mathrm{X}$.

\section{J. Atomic Absorption Spectrophotometer analysis}

Shimadzu Atomic absorption spectrophotometer (Model number AA6300) was used to quantify the silver nanoparticles in leaves, shoots, and roots of Vigna radiata plant. The samples were rinsed with distilled water and slice into small pieces. Samples of 3 grams were oven dried at $70^{\circ} \mathrm{C}$ for 24 hours, and dry weight of sample was calculated. The dried sample was then placed in muffle furnace at $700^{\circ} \mathrm{C}$ for 15 hours. The ash was dissolved in $5 \mathrm{ml}$ of $20 \%$ of $\mathrm{HCl}$. Samples were covered and heated on a hot plate until boiling. $10 \%$ of $\mathrm{HCl}$ was added to avoid drying of the sample. $1 \mathrm{ml}$ of $\mathrm{HNO}_{3}$ and $3 \mathrm{ml}$ of $\mathrm{HCl}$ were added after the sample was cooled to room temperature. Samples were filtered and final volume will be adjusted with $10 \%$ of $\mathrm{HCl}$.

\section{RESULT AND DISCUSSION}

A gram negative, pink colour lactose fermenting colonies was isolated from bovine milk sample. The $16 \mathrm{~S}$ rRNA gene sequence analysis was done to explicate the taxonomic position and relationships amongst closely related species. The BLAST search of the 16S rRNA sequences (1251 base pairs) of the bacterium showed $89.17 \%$ similarity with Klebsiella sp. OS1 (KU253719.1), Klebsiella sp. CCFM8375 (KJ803932.1) and Klebsiella sp. CCFM8376 (KJ803933.1). Based on the molecular taxonomy and phylogeny, it was identified as Klebsiella pneumoniae and designated as Klebsiella pneumoniae STC4. The 16S rRNA gene partial sequence of the bacterium was deposited in NCBI and got the accession number (MT348347.1). A Maximum Likelihood tree based on 16S rRNA sequence of Klebsiella pneumoniae strain STC4 showed that, the isolate occupied a distinct phylogenetic position within the representatives of the Klebsiella family (Figure 1). In the phylogenetic tree, number of nodes indicated the ranks of bootstrap support based on 1000 resampled data sets analysis. The scale bar indicated 0.0050 substitutions per nucleotide position. The tree with the highest log likelihood (-2713.34) was shown. Initial tree for the experimental search were obtained using Neighbor-Join and BioNJ algorithms to a matrix of pairwise distances and these were assessed by Tamura-Nei model by choosing the topology with larger log likelihood data [20]. This analysis involved 15 nucleotide sequences with a total of 1476 positions in the dataset.

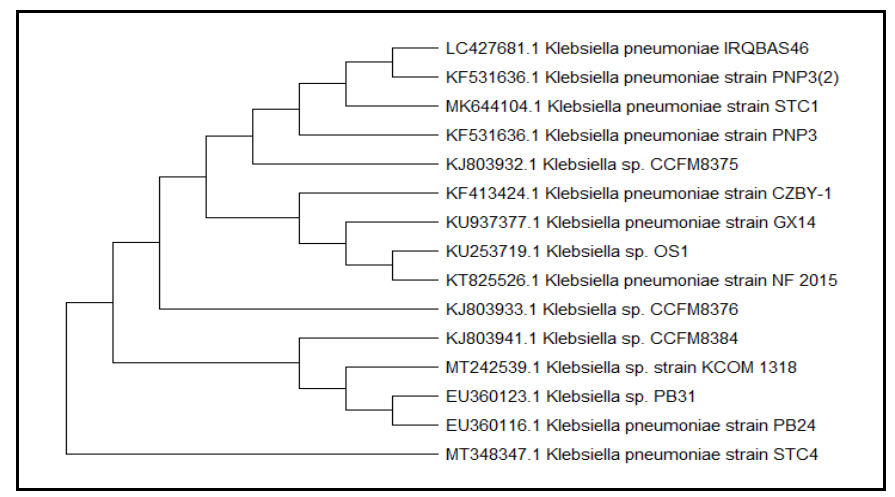

Fig. 1. Relationships between Klebsiella pneumonia STC4 and other members of Klebsiella pneumonia on rooted phylogenetic tree

The biosynthesis of silver nanoparticles was examined using the bacterial supernatant primarily through the observation of colour change of the experimental sample in the presence of $10 \mathrm{mM}$ of silver nitrate. A colour change from pale yellow to brown occurred in 24 hours. The intensity of the colour increased with period of incubation due to the reduction of Silver. Control exhibited no colour change in the bacterial culture when incubated in the same duration and condition. The colour change was due to excitation of surface plasmon vibrations that was characteristic to silver nanoparticles and these vibrations occurred due to arising dipole oscillation when an electromagnetic field in the visible range was coupled with the collective oscillations of conduction electrons [21].

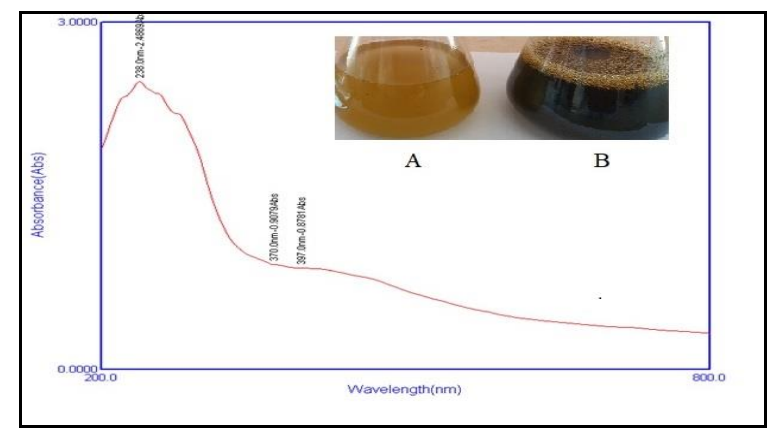

Fig. 2. The absorption spectrum of silver nanoparticles synthesized by Klebsiella pneumonia STC4 culture supernatant. Inset showed the visual observation of colour change during the biosynthesis (A) Flask

with medium and silver nanoparticles, no colour change after 24

hours (b) Flask with medium with Klebsiella pneumonia STC4

culture supernatant, colour changed to brown in 24 hours

The primary characterization of biosynthesized nanoparticles by UV-Visible spectrophotometer has been confirmed to be a very suitable technique for the analysis of silver nanoparticles [22]. A strong peak specific to silver nanoparticles was observed at $397 \mathrm{~nm}$ (Figure 2). Similar to our findings, other researchers have also reported the 
formation of silver nanoparticles by exhibiting the typical surface plasmon absorption maxima at nearly $397 \mathrm{~nm}$ from the UV-Visible spectrum [23,24].

The TEM examination of the prepared silver nanoparticles clearly confirmed the presence of spherical nanoparticles of varying sizes (Figure 3 ). The SAED pattern showed that the synthesized silver nanoparticles were crystalline in nature. The size of nanoparticles ranged between 5 to $20 \mathrm{~nm}$.

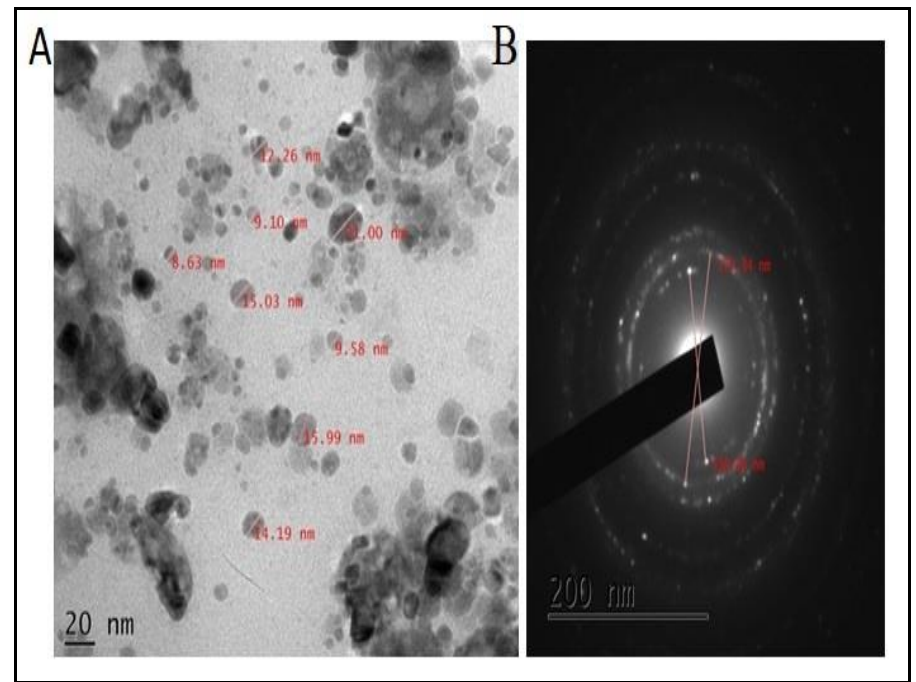

Fig. 3. TEM micrograph of silver nanoparticles (A) along with SAED pattern

In the present study, we assessed the impact of silver nanoparticles on the most sensitive stages of plant development, i.e. seed germination and seedling growth of Vigna radiata plant. Among the germination indices, seed germination rate was affected at higher concentration of silver nanoparticles (10,000ppm). In control and 8000ppm concentration, the seed germination was $92 \%$. On the other side, 2000 to $6000 \mathrm{ppm}$ of silver nanoparticles concentration (98 to 100\%) promoted the germination of seeds compared to control (92\%).

The effect of silver nanoparticles on shoot and root lengths, number of leaves of mung bean were shown in Table 1. It was observed that with increase in silver nanoparticles concentration, the shoot and root lengths also increased. However, after certain concentration (8000ppm), the root and shoot was found to decline. 6000ppm of silver nanoparticles found to promote root and shoot elongation better than other concentrations and control. All the concentrations of silver nanoparticles responded well compared to control (Figure 4).
Table 1- Effect of silver nanoparticles on root, shoot lengths of Vigna radiata plant

\begin{tabular}{|c|c|c|c|c|c|c|c|c|c|}
\hline \multirow[b]{2}{*}{$\begin{array}{c}\text { Concentration } \\
\text { (ppm) }\end{array}$} & \multicolumn{3}{|c|}{ Day 4} & \multicolumn{3}{|c|}{ Day 7} & \multicolumn{3}{|c|}{ Day 15} \\
\hline & $\begin{array}{l}\text { Root } \\
\text { length } \\
(\mathrm{cm})\end{array}$ & $\begin{array}{l}\text { Shoot } \\
\text { length } \\
(\mathrm{cm})\end{array}$ & $\begin{array}{l}\text { Number } \\
\text { of leaves }\end{array}$ & $\begin{array}{l}\text { Root } \\
\text { length } \\
(\mathrm{cm})\end{array}$ & $\begin{array}{l}\text { Shoot } \\
\text { length } \\
(\mathrm{cm})\end{array}$ & $\begin{array}{l}\text { Number } \\
\text { of leaves }\end{array}$ & $\begin{array}{l}\text { Root } \\
\text { length } \\
(\mathrm{cm})\end{array}$ & $\begin{array}{l}\text { Shoot } \\
\text { length } \\
(\mathrm{cm})\end{array}$ & $\begin{array}{l}\text { Number } \\
\text { of leaves }\end{array}$ \\
\hline Control & $1.17=0.9$ & $2.83 \pm 2.1$ & $1.67 \pm 0.8$ & $2.4=1.7$ & $6.9=2.6$ & $1.8 \pm 0.5$ & $3.42 \pm 0.9$ & $10.84=1.8$ & $1.8 \pm 0.5$ \\
\hline 2000 & $1.90=1.1$ & $4.43 \pm 2.8$ & $1.40=0.9$ & $2.5 \pm 0.9$ & $8.9=2.8$ & $1.7 \pm 0.9$ & $3.72=1.1$ & $14.12=1.6$ & $1.7 \pm 0.9$ \\
\hline 4000 & $1.90=1.4$ & $4.40 \pm 2.2$ & $1.30=0.9$ & $2.7 \pm 1.1$ & $9.3 \pm 3.2$ & $1.8 \pm 0.6$ & $4.12=1.7$ & $20.27 \pm 2.4$ & $1.8 \pm 0.6$ \\
\hline 6000 & $2.60 \pm 1.7$ & $4.92 \pm 2.5$ & $1.30=0.9$ & $3.4 \pm 2.1$ & $9.5=2.2$ & $1.8 \pm 0.6$ & $4.42=0.6$ & $21.80=1.8$ & $1.8 \pm 0.6$ \\
\hline 8000 & $2.20=1.1$ & $5.10=2.2$ & $1.60=0.8$ & $3.2 \pm 1.6$ & $8.7 \pm 1.8$ & $1.8 \pm 0.6$ & $3.52=0.9$ & $19.60=4.4$ & $1.8 \pm 0.6$ \\
\hline 10000 & $2.10=0.9$ & $4.60=1.9$ & $1.60 \pm 0.9$ & $3.1 \pm 0.8$ & $6.3 \pm 2.8$ & $1.8 \pm 0.9$ & $3.32 \pm 2.1$ & $11.93 \pm 3.80$ & $1.8 \pm 0.9$ \\
\hline
\end{tabular}

The values are expressed in Mean \pm Standard Deviation

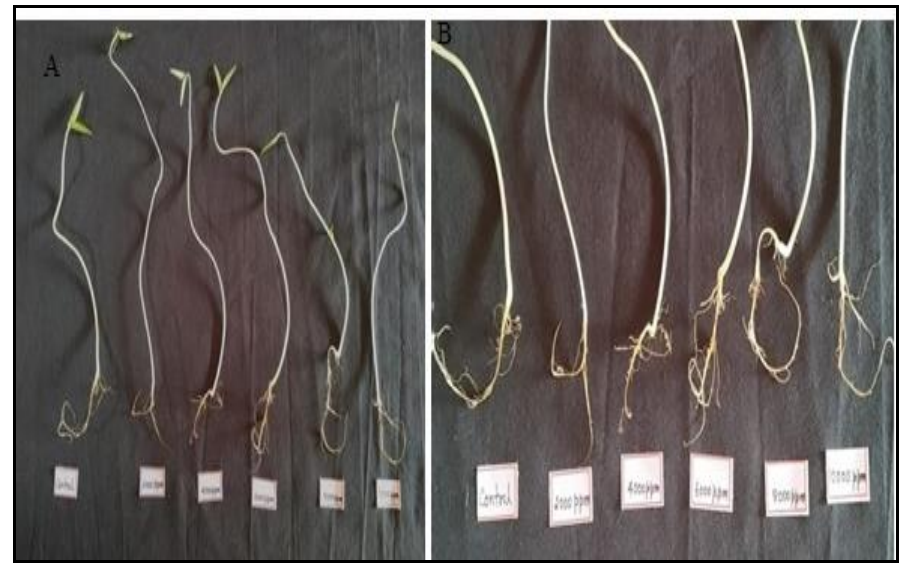

Fig. 4. Shoot (A) and root (B) length of Vigna radiata plant at different concentrations of silver nanoparticles

The mung bean leaves appeared first in the control plants. There was no significant difference in control and other concentrations on $7^{\text {th }}$ and $15^{\text {th }}$ day observations. Salama reported that small concentration of silver nanoparticles had a stimulating effect on the growth of the plantlets, while the enhanced concentrations induced an inhibitory effect in Phaseolus vulgaris L. and Zea mays L. [25] Odayar and his colleagues reported that silver nanoparticles incorporated into the growth medium does not affect plant growth at low concentrations but at higher concentrations it showed a toxic effect to plant growth inhibiting root formation and shoot elongation in Trichilia dregeana [26].

The effect of silver nanoparticles on fresh and dry weight of the plant was shown in Table 2. The 6000ppm of silver nanoparticles treated Vigna radiata plant showed increase in fresh weight $15 \%$ and $22 \%$ in dry weight over control. At the highest concentration of $10000 \mathrm{ppm}$, mung bean showed increase in fresh weight $6.25 \%$ and $8.9 \%$ in dry weight over control. The fresh and dry weights were both significantly higher than those of the untreated plants (Control). 
Table 2 - Effect of silver nanoparticles on fresh and dry weights of Vigna radiata plant

\begin{tabular}{|c|c|c|}
\hline $\begin{array}{c}\text { Concentration } \\
(\mathbf{p p m})\end{array}$ & $\begin{array}{c}\text { Weight of fresh leaves } \\
\text { (grams) }\end{array}$ & $\begin{array}{c}\text { Weight of dry } \\
\text { leaves (grams) }\end{array}$ \\
\hline Control & 0.120 & 0.051 \\
\hline 2000 & 0.132 & 0.051 \\
\hline 4000 & 0.135 & 0.053 \\
\hline 6000 & 0.141 & 0.065 \\
\hline 8000 & 0.123 & 0.061 \\
\hline 10000 & 0.128 & 0.056 \\
\hline
\end{tabular}

In general, the leaf surface area of the tested mung bean plant was significantly increased as the silver nanoparticles increased till $8000 \mathrm{ppm}$. The leaf surface area showed maximum size at $6000 \mathrm{ppm}$. At highest concentration $10000 \mathrm{ppm}$, decline in leaf surface area was observed in the tested plant. These results were confirmed by results obtained from other studies [25].

Table 3 - Effect of silver nanoparticles on leaf surface area of Vigna radiata plant

\begin{tabular}{|c|c|}
\hline $\begin{array}{c}\text { Concentration } \\
(\mathbf{p p m})\end{array}$ & $\begin{array}{c}\text { Leaf surface area } \\
\left(\mathbf{c m}^{\mathbf{}}\right)\end{array}$ \\
\hline Control & $2.86 \pm 0.2$ \\
\hline 2000 & $3.07 \pm 0.2$ \\
\hline 4000 & $3.5 \pm 0.3$ \\
\hline 6000 & $3.57 \pm 0.3$ \\
\hline 8000 & $3.36 \pm 0.4$ \\
\hline 10000 & $1.83 \pm 0.3$ \\
\hline
\end{tabular}

The values are expressed in Mean \pm Standard Deviation

Vigour Index calculated from percentage seed germination and plant indicated the capacity for survival or strong healthy growth in plant. Results of the present study showed decrease in vigour index in nanoparticles treated seedlings compared control (Figure 5). As nanoparticle concentration increased the vigour index decreased. Maximum vigor index was observed at 6000ppm. Vigour index was lower than control at $10000 \mathrm{ppm}$. Such inhibitory effects of nanoparticles were also reported by Lin and Xing in 2007 and Bagawade and Jagtap in 2018 on radish, rye grass and wheat plant $[17,27]$.

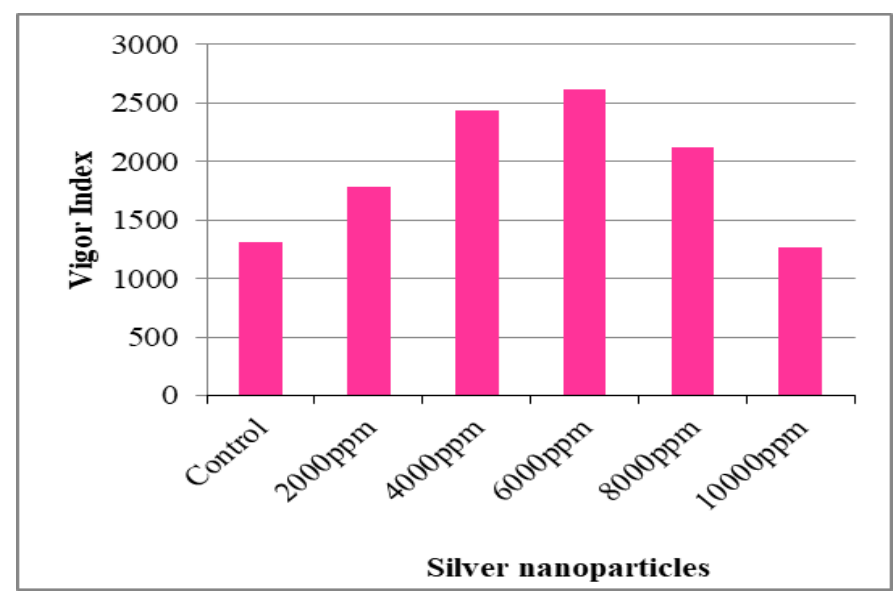

Fig. 5. Vigour index vs. Samples of Vigna radiata plant

Photosynthesis was the prime source of energy for the growth of all plants, because chlorophyll (Chl) represented an important pigment for photosynthesis. The photosynthetic reaction was divided into primary reaction, photosynthetic electron transport, photophosphorylation, and carbon assimilation [28]. Chlorophyll a $(\mathrm{Chl} a)$ and chlorophyll b $(\mathrm{Chl} b)$ were essential for the primary reaction. Chl $a$ and $\mathrm{Chl} b$ absorbed sunlight at different wavelengths. Chl $a$ mainly absorbed red-orange light and $\mathrm{Chl} b$ mainly absorbed bluepurple light, leading to the assumption that the total amount leaf chlorophyll content $(\mathrm{Chl} a+b)$ and allocated ratio $(\mathrm{Chl} a / b)$ directly influenced the photosynthetic capacity of plants [28]. This hypothesis had been confirmed by a controlled experiment by means of numerous plant species.

Effect of silver nanoparticles on chlorophyll A and B, total chlorophyll of Vigna radiata plant showed significant increase above control until 6000ppm as shown in Figure 6. These results were confirmed by results obtained from other studies [29]. They demonstrated that chlorophyll A content increased significantly by silver nanoparticles in Sorghum [29].

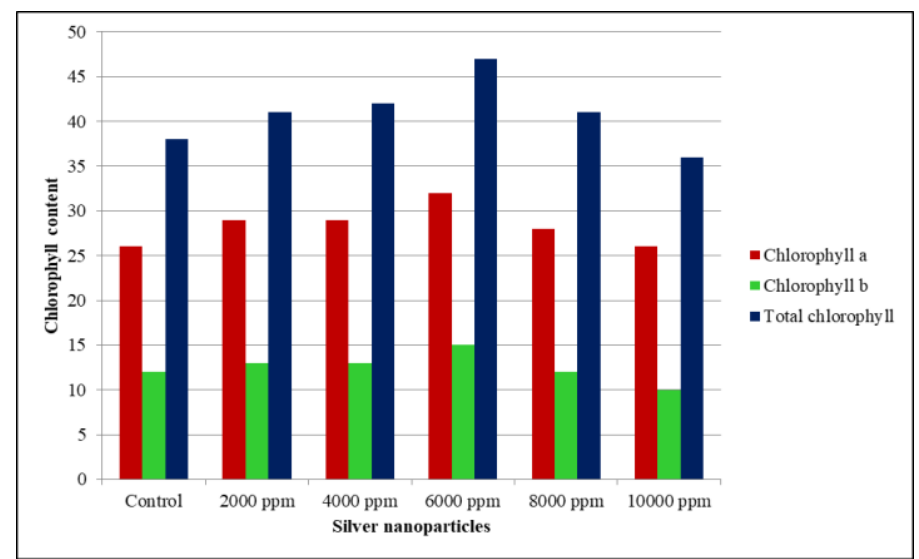

Fig. 6. Effect of silver nanoparticles on chlorophyll content of Vigna radiata plant 
The effect of silver nanoparticles on carotenoid content of mung bean showed significant increase above control as shown in Table 4. The best results were found at 6000ppm silver nanoparticles. In concentration 6000ppm, carotenoid content increased by $10 \%$ compared to the control and when the concentration increased, carotenoid contents got decreased. These results were confirmed by results obtained from other studies [25].

Table 4 - Effect of silver nanoparticles on carotenoid content of Vigna radiata plant

\begin{tabular}{|c|c|}
\hline Concentration (ppm) & Carotenoid $(\mathbf{m g} / \mathbf{g})$ \\
\hline Control & 3.31 \\
\hline 2000 & 3.49 \\
\hline 4000 & 3.52 \\
\hline 6000 & 3.64 \\
\hline 8000 & 3.06 \\
\hline 10000 & 3.04 \\
\hline
\end{tabular}

The microscopic observation of leaves, stem and roots of Vigna radiata plant revealed the presence of silver nanoparticles.

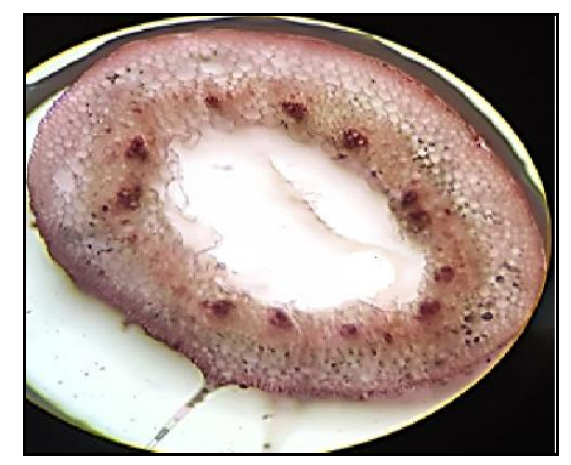

Fig. 7. Microscopic observation of Vigna radiata plant root treated at $10000 \mathrm{ppm}$ concentration of silver nanoparticles

In table 5, the result showed the accumulated concentration of silver nanoparticles in root, stem and leaves of Vigna radiata plant. It was observed that the plant seeds uptake silver nanoparticles within fifteen days. The stem accumulated varied between $84.3 \mathrm{ppm}$ and $120.83 \mathrm{ppm}$ from 2000 and 10000ppm concentrations of silver nanoparticles respectively. There was a slight difference in the translocation of silver nanoparticles in stem in different concentrations.

The leaves accumulated 18ppm and 607.1ppm from 2000 and $10000 \mathrm{ppm}$ concentrations of silver nanoparticles respectively. There was a 30 fold increase in silver nanoparticles translocated in leaves from 2000ppm to 10000 ppm concentrations. Subsequently the accumulation of nanoparticles was more in leaves; therefore it could disrupt the synthesis of chlorophyll in leaves and thus affected the photosynthetic system of the plant.

The roots accumulated $336.4 \mathrm{ppm}$ to $1238.2 \mathrm{ppm}$ from 2000 to10000ppm of silver nanoparticles concentrations. The uptake of silver nanoparticles was thrice from 2000 to 10000ppm concentrations. Peng and his colleagues in 2017 reported the accumulation of copper oxide nanoparticles in roots [30]. Stegemier and his colleagues in 2017 reported that silver nanoparticles were distributed throughout the root tip and showed highest concentration near the apical meristem [31].

Table 5- Different concentrations of silver nanoparticles accumulated at roots, stem and leaves of Vigna radiata plant analysed by Atomic Absorption Spectrophotometer (AAS)

\begin{tabular}{|c|c|c|c|c|c|}
\hline $\begin{array}{c}\text { Plant } \\
\text { part }\end{array}$ & 2000ppm & 4000ppm & $\mathbf{6 0 0 0 p p m}$ & $\mathbf{8 0 0 0 p p m}$ & $\mathbf{1 0 0 0 0 p p m}$ \\
\hline Roots & $336.4 \mathrm{ppm}$ & $693.5 \mathrm{ppm}$ & $786.7 \mathrm{ppm}$ & $951.8 \mathrm{ppm}$ & $1238.2 \mathrm{ppm}$ \\
\hline Stem & $84.3 \mathrm{ppm}$ & $101.3 \mathrm{ppm}$ & $107.96 \mathrm{ppm}$ & $116.23 \mathrm{ppm}$ & $120.83 \mathrm{ppm}$ \\
\hline Leaves & $18 \mathrm{ppm}$ & $30 \mathrm{ppm}$ & $42.8 \mathrm{ppm}$ & $55.9 \mathrm{ppm}$ & $607.1 \mathrm{ppm}$ \\
\hline
\end{tabular}

\section{CONCLUSION}

The results of the present study clearly indicated that the small concentrations of silver nanoparticles promoted the growth of seed germination and its vigour index, while the largest concentration induced an inhibitory effect on Vigna radiata plant. Reports regarding the accumulation of nanoparticle on seeds were very limited, so this kind of study should be quite useful in predicting the uptake of nanoparticle during seed germination and its growth.

\section{ACKNOWLEDGEMENT}

Authors thank Sophisticated Test and Instrumentation centre, Cochin University of Science and Technology, Cochin, Kerala, Instrumentation center, Ayya Nadar Janaki Ammal College, Sivakasi, and Yaazah Xenomics, Coimbatore for performing HR-TEM, AAS, and 16S rRNA sequencing.

\section{REFERENCE}

[1] B.S. Sekhon, "Nanotechnology in agri-food production: An overview", Nanotechnology, Science and Applications, Vol. 7, pp.31-53, 2014.

[2] Y. An and C. Zhong, "Impacts of silver nanoparticles on plants: A focus on the phytotoxicity and underlying 


\section{International Journal of Engineering Applied Sciences and Technology, 2020 \\ Vol. 5, Issue 2, ISSN No. 2455-2143, Pages 274-281 \\ Published Online June 2020 in IJEAST (http://www.ijeast.com)}

mechanism", International Journal of Molecular Sciences, Vol. 20, pp. 1-21, 2019.

[3] S. Alavi and A. Dehpour, "Evaluation of the nanosilver colloidal solution in comparison with the registered fungicide to control greenhouse cucumber downy mildew disease in the north of Iran", Proceedings of the VI International Postharvest Symposium, Antalya, Turkey, pp. 1643-1646, 2010.

[4] T. Vinkovic, O. Novak, M. Strnad, W. Goessler, D.D. Jurasin, N. Paradikovic, and I.V. Vrcek, "Cytokinin response in pepper plants (Capsicum annuum L.) exposed to silver nanoparticles", Environmental Research, Vol. 156, pp. 10-18, 2017.

[5] E. Lombi, E. Donner, K.G. Scheckel, R. Sekine, C. Lorenz, N.V. Goetz, and B. Nowack, "Silver speciation and release in commercial antimicrobial textiles as influenced by washing", Chemosphere, Vol. 111, pp. 352-358, 2014.

[6] J. Hedberg, S. Skoglund, M.E. Karlsson, S. Wold, W.I. Odnevall, and Y. Hedberg, "Sequential studies of silver released from silver nanoparticles in aqueous media simulating sweat, laundry detergent solutions and surface water", Environmental Science and Technology, Vol. 48, pp. 73147322, 2014.

[7] F. Gottschalk, and B. Nowack, "The release of engineered nanomaterials to the environment", Journal of Environmental Monitoring, Vol. 13, pp. 1145-1155, 2011.

[8] H. Zhu, J. Han, J.Q. Xiao, and Y. Jin, "Uptake, translocation, and accumulation of manufactured iron oxide nanoparticles by pumpkin plants", Journal of Environmental Monitoring, Vol. 10, pp. 713-717, 2008.

[9] R.D. Handy, R. Owen, and E. Valsami-Jones, "The ecotoxicology of nanoparticles and nanomaterials: Current status, knowledge gaps, challenges, and future needs", Ecotoxicology, Vol. 17, pp. 315-325, 2008.

[10] J.D. Judy, and P.M. Bertsch, "Bioavailability, toxicity and fate of manufactured nanomaterials in terrestrial ecosystems". In: Sparks DL, editor. Advances in Agronomy. United States: Academic Press, pp. 1-64, 2014.

[11] S. Wang, J. Lv, J. Ma, and S. Zhang, "Cellular internalization and intracellular biotransformation of silver nanoparticles in Chlamydomonas reinhardtii", Nanotoxicology, Vol. 10, pp. 1129-1135, 2016.

[12] J. Geisler-Lee, M. Brooks, J. Gerfen, Q. Wang, and C. Fotis, "Reproductive toxicity and life history study of silver nanoparticle effect, uptake and transport in Arabidopsis thaliana", Nanomaterials, Vol. 4, pp. 301-318, 2014.

[13] A. Montes, M.A. Bisson, J.A. Gardella, and D.S. Aga, "Uptake and transformations of engineered nanomaterials: Critical responses observed in terrestrial plants and the model plant Arabidopsis thaliana", Science of the Total Environment, Vol. 607-608, pp. 1497-1516, 2017.

[14] P. Zhang, Y. Ma, Z. Zhang, X. He, and Z Guo, "Comparative toxicity of nanoparticulate/bulk $\mathrm{Yb}_{2} \mathrm{O}_{3}$ and $\mathrm{YbCl}_{3}$ to cucumber (Cucumis sativus)", Environmental Science and Technology, Vol. 46, pp.1834-1841, 2012.

[15] I. Moreno-Garrido, S. Perez, and J. Blasco, "Toxicity of silver and gold nanoparticles on marine microalgae", Marine Environmental Research, Vol. 111, pp. 60-73, 2015.

[16] C. Ma, J.C. White, O.P. Dhankher, and B. Xing, "Metal based nanotoxicity and detoxification pathways in higher plants", Environmental Science and Technology, Vol. 49, pp. 7109-7122, 2015.

[17] J.A. Bagawade, and S.S Jagtap, "Effect of Zinc oxide nanoparticles on germination and growth characteristics in Wheat plants (Triticum aestivum L.)", International Journal of Advance Engineering and Research Development, Vol. 5(4), pp. 204-209, 2018.

[18] H. Hu, J. Zhang, X. Sun, and X. Zhang, "Estimation of leaf chlorophyll content of rice using image color analysis", Canadian Journal of Remote Sensing, Vol. 39, pp. 185-190, 2013.

[19] H.K. Lichtenthaler, and A.R. Wellburn, "Determination of total carotenoids and chlorophylls A and B of leaf in different solvents". Biochemical Society Transactions, Vol.11, pp. 591$592,1983$.

[20] S. Kumar, G. Stecher, M. Li, C. Knyaz, and K. Tamura, "MEGA X: Molecular Evolutionary Genetics Analysis across computing platforms", Molecular Biology and Evolution, Vol. 35, pp. 1547-1549, 2018.

[21] D. Koilparambil, L. Kurian, S. Vijayan, and J.M. Shaikmoideen, "Green synthesis of silver nanoparticles by Escherichia coli: Analysis of antibacterial activity", Journal of Water and Environmental Nanotechnology, Vol. 1(1), pp. 6374, 2016.

[22] S. Gurunathan, K. Kalishwaralal, R. Vaidyanathan, D. Venkataraman, S. Pandian, M. Jeyaraj, H. Nellaiah, and S. Eom, "Biosynthesis, purification and characterization of silver nanoparticles using Escherichia coli", Colloids and surfaces. B: Biointerfaces, Vol. 74, pp. 328-335, 2009.

[23] M. Tripathi, A. Kumar, and S. Kumar, "Characterization of silver nanoparticles synthesizing bacteria and its possible use in treatment of Multi drug resistant isolate", Frontiers in Environmental Microbiology, Vol. 3(4), pp. 62-67, 2017.

[24] Kumar, N., Das, S., Jyoti, A. and Kaushik, S. "Synergistic effect of silver nanoparticles with Doxycycline against Klebsiella pneumoniae", International Journal of Pharmacy and Pharmaceutical Sciences, Vol. 8(7), pp. 183-186, 2016. 
[25] H.M.H. Salama, "Effects of silver nanoparticles in some crop plants, common bean (Phaseolus vulgaris L.) and corn (Zea mays L.)", International Research Journal of Biotechnology, Vol. 3(10), pp.190-197, 2012.

[26] K. Odayar, B. Odhav, and V. Mohanlall, "The role of nanoparticles on the plant growth of Orthodox and Recalcitrant seeds", Advances in Composites, Biocomposites and Nanocomposites, pp. 287-304, 2013.

[27] D. Lin, and B. Xing, "Phytotoxicity of nanoparticles: Inhibition of seed germination and root growth", Environmental Pollution, Vol. 150, pp. 243-350, 2007.

[28] H. Croft, J.M. Chen, X. Luo, P. Bartlett, B. Chen, and R.M. Staebler, "Leaf chlorophyll content as a proxy for leaf photosynthetic capacity”, Global Change Biology, Vol. 23, pp. 3513-3524, 2017.

[29] S. Karthick, and S. Chitrakala, "Ecotoxicological effect of Lecani cilium (Ascomycota: Hypocereales) based silver nanoparticles on growth parameters of economically important plants", Journal of Biopesticides, Vol. 4(1), pp. 97-101, 2011.

[30] C. Peng, C. Xu, Q. Liu, L. Sun, Y. Luo, and J. Shi, "Fate and transformation of $\mathrm{CuO}$ nanoparticles in the soil rice system during the life cycle of rice plants", Environmental Science and Technology, Vol. 51, pp. 4907-4917, 2017.

[31] J.P. Stegemeier, B.P. Colman, F. Schwab, M.R. Wiesner, and G.V. Lowry, "Uptake and distribution of silver in the aquatic plant Landoltia punctata (duckweed) exposed to silver and silver sulfide nanoparticles", Environmental Science and Technology, Vol. 51, pp. 4936-4943, 2017. 